\title{
O CASAL INFÉRTIL, SENTIMENTOS E SEXUALIDADE
}

\author{
Vitória Menezes ${ }^{1}$
}

\section{THE INFERTILE COUPLE \\ - FEELING AND SEXUALITY}

\begin{abstract}
Resumo: Este texto convida à reflexão sobre a infertilidade conjugal. Contextualiza a dificuldade no momento atual, ressaltando a dor psicológica e o desamparo que o casal infértil carrega frequentemente, não apenas pela simples ausência do filho, mas também pelas repercussões que o fato ocasiona na família de origem e na rede social. Sem direito a revelar tal dor, o casal é estimulado a dissimulá-la. Assim, com a vida estagnada, sem direito a outros planos, diante de tantos compromissos financeiros, adiam-se outras metas, o que traz mudanças e frustraçóes evidentes, inclusive na vivência da sexualidade.
\end{abstract}

Palavras-chave: Sexualidade; infertilidade; relações familiares.

\begin{abstract}
This text invites to a reflection on the conjugal infertility. It contextures the actual difficulty, standing out psychological pain and abandonment that the infertile couple loads frequently, not only for the simple absence of the son, but also for the repercussions that the fact causes in the origin family and on social net. With no right to disclose such pain, the couple is stimulated to dissimulate it. Thus, with the stop of life flow, without right to other plans, ahead of many financial commitments, other goals are procrastinated, what brings evident changes and frustrations, which compromise even the experiences of sexuality.
\end{abstract}

Keywords: Sexuality; infertility; family relations.

\footnotetext{
Psicóloga. Pós-graduada em educação sexual pelo CEUB/CESEX. Pós-graduada em psicologia familiar e realidade social pela FAFIRE. Especialista em sexologia clínica pela FLASSES. e-mail: vitmenezes@terra.com.br
} 
A sexualidade humana pode ser exercida de várias formas, mas, a rigor, existem três funções básicas: reprodução, prazer e comunicação interpessoal. Dentro dessas funções, as pessoas encontram formas individuais para exercêla, nem sempre bem aceitas pelo grupo ao qual pertencem.

É a reprodução sua função mais elementar, a mais conhecida e aceita socialmente, talvez por depender dela a própria perpetuação da espécie. Embora exercendo o sexo uma função biológica, é a adaptação sócio-cultural, juntamente com a percepção que o indivíduo abstrai dela, que determinará o modo como sua sexualidade será vivenciada.

A busca pela melhoria no desempenho sexual é historicamente masculina, possivelmente impulsionada pela concepção imperativa do "sexo-reprodução", uma vez que a resposta sexual masculina é fundamental para a procriação. No entanto observa-se um crescente número de mulheres buscando auxílio para melhorar a vivência de sua sexualidade. Tal fato muito provavelmente só veio à tona quando a mulher conseguiu sua liberdade sexual com o advento da pílula anticonceptiva, deflagrando a "Revolução Sexual", que, em verdade, foi um movimento indefinido de contestação da moral tradicionalista e o grande marco da idéia de que a mulher agora, poderia exercer o controle sobre sua fertilidade, dissociando o sexo-reprodução do sexo-prazer (CAVALCANTI, CAVALCANTI, 1992).

Na prática, a realidade pode não ser esta. Atordoados, alguns casais frustramse ao constatar que sexo sem qualquer medida anticonceptiva pode não ser sinônimo necessariamente de "gravidez", ao contrário de outros tantos que se tornam pais sem desejar, planejar ou estarem preparados. Para estes casais, "planejar uma gravidez" não é o suficiente para gestar.

Uma falha "humana" ou até "mecânica" é, em nossa sociedade, muito mais aceita do que uma incapacidade física que impeça um casal de gerar e ver nascer seus próprios filhos.

Embora se acredite ser a fecundidade uma bênção divina, os jovens estão protelando o casamento, assim como a chegada dos filhos, por motivos os mais diversos (MALDONADO, 1985), dentre os quais o novo papel da mulher na sociedade, sua preocupação em conquistar o espaço profissional, visando, inclusive, desfrutar de mais estabilidade financeira para si e também para os futuros filhos. Pode-se atribuir, aliás, justamente à mudança do papel feminino, a maior dificuldade em se obterem "babás de confiança", tias e vovós “ávidas” para auxiliar as mamães a exercerem a maternagem. 
A família de "dois salários" sugere que marido e mulher dividam as tarefas, deixando para bem longe a figura da mulher que podia "pedir demissão para cuidar da prole". O re-casamento une pessoas até então "convictas" de que estavam satisfeitas com o número de filhos que tinham. Utilizaram-se por isso de métodos contraceptivos "irreversíveis" e agora, diante de uma nova relação, a "convicção" anterior cede lugar ao desejo de engravidar e conviver com um novo filho.

Outro fator importante é que uma mulher "balsaquiana" esqueceu o limite da idade. Não é raro atletas, atrizes e mulheres de uma forma geral chegarem perto dos 40 anos esbanjando juventude e entusiasmo, em belas formas físicas. Provavelmente a aparência externa conduz ao esquecimento de que, ao contrário do corpo e da mente, os seus ovários dependem do relógio biológico.

Motivos à parte, a constatação é que sem esquecer o desejo de ter um filho, adia-se o projeto.

Mesmo com a taxa de fecundidade em baixa, o exemplo das avós e mães que tiveram o número de filhos que pretendiam ou ultrapassaram suas próprias expectativas está presente, fortalecendo-se a idéia de que a qualquer tempo não se terá dificuldade em engravidar. No entanto, na reprodução, nem sempre é a idade o fator limitante.

Muitas vezes a constatação de uma dificuldade orgânica, anteriormente não percebida e tratada, leva à frustração por impossibilitar a realização do sonho de ter seus próprios filhos. Antes impensável, a reprodução assistida (RA) é hoje uma alternativa segura, embora onerosa, que oferece, dependendo do caso, um índice de sucesso em torno dos 30\%. Embora sendo consenso que o casal necessita de apoio psicológico, não é exigida a presença do psicólogo nas clínicas de reprodução assistida no Brasil para lhes dar assistência à probabilidade de $70 \%$ de insucesso.

Desde o nascimento do primeiro bebê de proveta, na Inglaterra, em 1978, a sociedade tenta adaptar-se à realidade de as crianças serem geradas, agora, em laboratório, longe das relações sexuais, com todas as implicações éticas e morais que envolvem o tema (TESTART, 1998). Aprimoram-se espantosamente o conhecimento técnico possibilitando vencer desafios impensáveis, enquanto o estudo do comportamento psicológico do casal assistido em RA ainda "engatinha".

Neste sentido, são raras as publicações científicas sobre a psicologia de casais inférteis, estando a socialização desse conhecimento restrita a modestos 
encontros científicos, embora o meio médico atribua sempre ao estado psicológico do casal, fator relevante, principalmente em se tratando da necessidade de, diante de um fracasso, reagir positivamente.

Reproduzir é copiar, proliferar. Procriar é dar origem, nascimento. Reprodução diz respeito à fecundação, à união bem sucedida do espermatozóide com o óvulo, que dará origem ao embriāo. Por outro lado, procriar é dar origem ao concepto. Assim, nem toda reprodução chegará à procriação, pois pode haver uma interrupção. Reprodução tem relação com gestação, enquanto que "procriação" pressupõe paridade.

\section{Infertilidade}

A ausência de procriação define infertilidade. $O$ casal infértil é aquele que não teve filhos, seja qual tenha sido a causa (voluntária, fisiológica, etc.). $\mathrm{Na}$ atualidade, é pertinente considerar que a esterilidade é um caso particular de infertilidade que pode ser definida como a "incapacidade de procriar". Salvo em casos bem definidos, por ausência de ovários, trompas, espermatozóides, etc., "[...] a esterilidade só é certa, no final da vida reprodutiva" (TESTART, 1998, p.105).

Talvez tenha sido a falta de conhecimento sobre o esperma, associada ao mito de que potência sexual estava relacionada à fertilidade, além da "conveniência masculina”, que durante muitos anos os homens estiveram distantes do tratamento de infertilidade. Sem sombra de dúvida, a própria medicina exerceu um papel marcante para a manutenção de tal equívoco. Os pesquisadores, quando muito, analisavam o conteúdo ejaculado apenas pelo prisma da quantidade, ignorando o potencial de fertilização e a qualidade. Mesmo isolando-se o preconceito, é verdadeiro e inquestionável o fato de o aparelho reprodutor feminino ser muito mais complexo que o masculino no que diz respeito à procriação. A mulher além de "ceder" sua célula germinativa irá promover condiçôes ideais para o encontro do óvulo com o espermatozóide, abrigar e desenvolver o ovo até sua completa maturação, quando então ocorrerá o parto.

\section{O desejo de ter um filho}

Maldonado (1985) cita a maternidade e a paternidade como fases do desenvolvimento psicológico. Lembra ainda um aspecto histórico relevante: “[...] Desde muitos séculos, a fecundidade é tida como benção divina, ao passo que a infertilidade é tida como castigo" (p. 14). 
Tal preocupação encontra-se descrita nos livros sagrados. Observa-se em Gênesis 9. 1: "Deus os abençoou Noé e seus filhos e disse: Sede fecundos, multiplicai-vos, enchei a terra". Ainda no Gênesis, 17.6 "E Abraão caiu com a face por terra. Deus lhe falou assim: [...] Eu te tornarei extremamente fecundo, de ti farei nações e reis sairão de ti” (BÍBLIA, 1973).

O desejo de formar uma prole é expresso em cerimônias de casamentos nas igrejas cristãs. É comum, por exemplo, o celebrante fazer menção aos futuros filhos do casal como "benção do céu".

Com o surgimento da pílula anticoncepcional, as mulheres passaram a contar com um grande aliado para a vivência sexual, desvinculando-se sexualidade da paridade: o planejamento familiar. Por outro lado, a RA trouxe para muitos a viabilização técnica que possibilita livrar-se da fatalidade bíblica, o castigo da infertilidade.

Não apenas a utilização de métodos anticoncepcionais confiáveis, mas a própria história econômica, social fez aparecer em vários lugares do mundo um fenômeno característico dos nossos dias: A paridade diminuiu (TESTART, 1965; BRASIL, 2002). A família “encolheu”. Do modelo colonial, extensa, transformou-se e reduziu-se a duas gerações nucleares: pais e filhos. Esta diminuiu para monoparental (constituída por um dos pais e os filhos), reduzida a unipessoal (pessoas que moram sozinhas) (SOUZA, 1997).

O Brasil é um país de contrates. A má distribuição de renda constrói uma desigualdade social assustadora. Fenômenos meteorológicos como seca e enchente estão com freqüência nas mesmas páginas dos jornais, assim como desperdício e fome. A fertilidade da mulher brasileira parece também acompanhar tais contrastes. Se por um lado 20\% das mulheres brasileiras em idade fértil encontrarão dificuldade em engravidar, há também no país, 20\% de adolescentes com idade entre 13 e 19 anos que já enfrentaram uma gravidez, muitas vezes desejada por elas, mas “indesejável socialmente” (OLIVEIRA, 2001).

\subsection{Crendices sobre a fertilidade}

A manifestação do desejo de "ser fértil" mostra-se presente também nas manifestaçōes populares que estão impregnadas na cultura, como a origem da árvore de Natal, mais antiga que o próprio nascimento de Jesus Cristo, surgida entre o segundo e o terceiro milênio a.C., entre povos indo-europeus que a consideravam uma expressão da energia de fertilidade da Mãe Natureza, por isso lhe rendiam culto. Muito embora a páscoa represente o desejo da 
Igreja em produzir novos discípulos, um dos símbolos é o coelho, animal com capacidade de cobrir muitas fêmeas, ejaculando ligeiro assim tendo maior possibilidade de gerar mais filhotes. O ovo da páscoa lembra o nascimento, a fecundação, a vida. Ovos geram vida! E o chocolate, além de ser afrodisíaco, é excelente reparador de energias, afirmam seus fabricantes.

Também a fogueira nas festas juninas lembra fertilidade. Diz a lenda que Santa Isabel, já bastante idosa, engravidou por Obra e Graça do Espírito Santo. Necessitando de ajuda durante o parto e depois deste, combinou com sua prima Maria, que tão logo chegassem os primeiros sinais de proximidade do parto, acenderia a fogueira, para que a prima, avistando a fumaça entendesse que chegara a hora de socorrer Isabel (BÍBLIA, 1973). Dizem ainda que, a mulher que já madura prometer à Santa Isabel colocar em seu filho o nome de João, em breve receberá seu filho varão!

As noivas também têm suas crenças. A longa calda de seus vestidos representa a prole que por certo virá.

O Hinduísmo valorizava a castidade masculina, por duas razões: o receio de contaminação sexual e a certeza de que o sêmen é a base da força e da longevidade. "É largamente difundida a idéia de que o sêmen é armazenado num órgão especial, o cérebro. A pessoa que não elimina o sêmen torna-se um super-homem" (GREGERSEN, 1983, p. 214).

É interessante observar-se que as crendices estão a serviço da necessidade de um povo, associada ao desejo de melhor compreender a realidade. Na ocasião, deveria ser útil imaginar-se a mulher passiva, com pequeno ou nenhum papel na fecundação, ao contrário do homem que, ativo, receberia o reconhecimento social pela capacidade de gerar filhos.

\subsection{Exclusão}

A lei romana punia o celibato e a ausência de filhos. Ofereciam-se privilégios às pessoas com prole grande enquanto que os solteiros e aqueles que não tinham filhos sofriam desvantagens econômicas e também sociais (GREGERSEN, 1983). Talvez sejam justamente, as puniçōes sociais as mais perversas com os casais sem filhos. As crianças contam hoje com a tolerância do adulto e também com a visão do empresário, para terem livre acesso a qualquer canto, independente do local estar pronto para recebê-las ou do evento ser do seu interesse. Como a presença dos pais junto aos filhos é cada vez mais rara, em virtude da necessidade de se estender a jornada de trabalho, entre outros motivos, restaurantes e bares investem em atrativos principalmente no lazer para os 
menores, como forma de atrair o dinheiro dos pais. Hotéis de luxo fazem promoções facilitando a presença do hospede mirim, o que é muito bem visto pelos pais. Além de serem recebidos como cortesia, ainda contam com espaços como, por exemplo, o "da papinha" onde liquidificadores barulhentos às primeiras horas da manhã passam a incomodar hóspedes cujo interesse é bem outro. Espaços até então impensáveis para a criança como concertos, o trabalho do papai ou da mamãe, estabelecimentos bancários, cerimônias religiosas, entre outros, têm como certa a presença da criança, onde seus pais desejam que ela esteja. Muito embora já surjam locais, que não recebem crianças, estes são minoria, e muitas vezes a atitude é recriminada pela sociedade.

Por outro lado, muitos casais sem filhos queixam-se de serem excluídos pelos amigos de determinadas comemorações, sob a alegação de que se "tratava de uma festinha exclusiva para crianças", assim são "barrados". Faltam-lhes filhos, "o passaporte".

A contradição fica clara: embora o casal sem filhos tenha dificuldade em ser aceito nos eventos infantis, precisa necessariamente conviver com crianças. Elas estão em suas festas, invadem suas férias, muitas vezes sem limites, em ambientes impróprios, possivelmente, gerando incômodos aos demais freqüentadores.

Estas podem ser consideradas formas de punição pela infertilidade de um casal, que, além da dor pessoal, precisa lidar com a intromissão das crianças e com a exclusão dos eventos sociais voltados para elas. A estes fatos ainda se associam os segredos de família, uma dor ocultada, que forçosamente é publicamente evidenciada.

\section{Segredos de família}

\subsection{A dor ocultada}

Um casal que vive a ausência involuntária de filhos, muito provavelmente sofre. O sofrimento pode não ser apenas do par, mas também da família e dos amigos:

[...] Como os casais sentem-se frustrados em seus esforços para se tornarem pais, seus próprios pais podem sentir-se frustrados em seus esforços para se tornarem avós e mentores, e seus irmãos por sentirem-se frustrados em seus desejos de se tornarem tios. Freqüentemente, as emoçóes e pensamentos relativos à dor intergeracional, da infertilidade de um casal, permanecem secretos, e não declarados. (SCHAFFER, DIAMOND, 2002, p. 122). 
A sociedade interfere ao observar que os filhos de um casal ainda "não foram encomendados" e sem saber do real motivo procura convencê-lo de que a hora é esta! Por um lado, freqüentemente, a família e os amigos, bem-intencionados, são muitas vezes insensíveis e magoam com comentários e questionamentos. Uma infertilidade não se esconde por muito tempo (SCHAFFER, DIAMOND, 2002). Por outro lado, a mídia busca associar a imagem de uma pessoa feliz, junto a uma criança, bem vestida e alimentada, ainda usando fraldas descartáveis, mesmo que com dois ou três anos de idade. Um casal sem filhos é freqüentemente visto como "deficitário" e ameaçador para a sociedade. Falta-lhe um "presente de Deus", uma forma de consolidar a família, perpetuar-se, dar continuidade à linha da vida, imortalizar-se.

Geralmente as pessoas que passam por um tratamento prolongado para a infertilidade sentem-se isoladas de outras e, mesmo desejosas de partilhar a questão, tornam-se mais reclusas quando tratamentos controvertidos estão sendo realizados. Eles próprios tendem a não refletir sobre algum assunto mais polêmico que envolva o procedimento (SCHAFFER, DIAMOND, 2002). Em contrapartida, durante a anamnese para o tratamento da fertilidade podem vir à tona fatos do passado, desconhecidos do cônjuge, e que preferencialmente assim deveriam permanecer. Abortos, doenças sexualmente transmissíveis e outros fatos da vida sexual anteriormente vivida precisam ser expostos agora, trazendo lembranças pesarosas e difíceis para o casal, podendo muitas vezes ampliar sua dor.

Há casais que se isolam:

[...] da maior rede de apoio, bem como um do outro. Uma vez que não há novidades, começam a evitar eventos familiares, especialmente quando parentes grávidas ou bebês estão presentes. Deixam de contar até mesmo às pessoas quando surge uma gravidez, e depois, quando aborta (SCHAFFER, DIAMOND, 2002, p. 123).

\subsection{A Relação do Par}

Embora seja consenso que o bem estar psicológico do casal e a harmonia do par seja relevante para a superação da dificuldade em procriar, há poucos registros na literatura relativos à dor de não poder procriar:

[...] Após algum tempo, quando a infertilidade começa a parecer permanente, ela rouba do casal um senso de que são participantes da vida. A coerência de nascer, crescer, casar-se, ter filhos, depois netos, parece distorcer-se. $\mathrm{O}$ individuo sente-se frustrado, incapacitado e, às vezes, punido" (op. cit., 2002, p. 117). 
É comum mulheres relatarem que se sentem culpadas ou responsáveis pela infertilidade do par mesmo quando o marido é o parceiro que apresenta a dificuldade física. Não é raro o divórcio ser lembrado como alternativa freqüente.

Quanto à frustração diante do insucesso num procedimento, um outro aspecto também é relevante. Nem sempre é possível definir-se com certeza a causa de um insucesso na implantação de um embrião e, neste momento, pensa-se que, mesmo controladas as causas orgânicas, existem as emocionais e sua imponderável influência. Parece ser este o momento em que o estresse do casal chega ao nível máximo recorrendo-se inclusive à irracionalidade através das superstições. Em contrapartida, casais, mesmo frustrados pela infertilidade, conseguem manter relacionamentos conjugais nos quais há afeto e apoio, o que não resolve a frustração, mas auxilia sua superação.

[...] A infertilidade, como uma crise de vida, às vezes pode prosseguir por anos, deixando os casais em um estado de animação suspensa. De acordo com Burns (1987), para certos casais, esta espécie de ambigüidade, quanto aos limites, pode complicar as transiçôes normais do ciclo de vida pelas quais a família deve passar. Por causa da criança fantasiada que está psicologicamente presente, mas fisicamente ausente, tais casais podem adiar decisóes importantes, como mudanças de carreira profissional, compra de residência e viagens. As mulheres, que se submetem ao tratamento demorado para a infertilidade, freqüentemente relatam frustração por não serem capazes de experienciar a maternidade, nem buscar ativamente fontes alternativas de satisfação (op. cit., 2002, p. 121).

Este "estado de animação suspensa" muito provavelmente interfere no prosseguimento da vida natural do par, quando se adia a execução de outros planos, restringindo-os à chegada do bebê. Por outro lado, diante de uma tentativa frustrada, se ampliam também as perdas e a sensação de fracasso se sobressai. Confunde-se fertilidade e impotência.

\subsection{Fertilidade versus Impotência}

Sem sombra de dúvida, este equívoco é um peso maior para os homens, já que a mulher não necessita necessariamente de qualquer das fases da resposta sexual humana para engravidar, ao contrário do homem. No entanto, a mulher muitas vezes assume a dificuldade de ereção do parceiro como sendo uma questão pessoal. Passa a acreditar que ela não é capaz de despertar seu interesse, de provocar uma ereção.

Ao se conscientizar da infertilidade, o casal tende a vivenciar a experiência de forma diferente. Enquanto as mulheres se mostram angustiadas por não 
engravidarem, tornando-se ansiosas para solucionar a dificuldade, absorvendo a questão com humildade, os homens, por outro lado, parecem lidar com mais dificuldade com tais mecanismos emocionais e a maioria confunde infertilidade com impotência.

A cultura popular consagra essa tendência, como se constata nos versos do cearense Valdeto Bandívia, que Menezes (1990, p.42), ao traduzir a "vingança”" de um plantador de milho, diante da "autoridade" do juiz de direito, fazendo uma apologia à família numerosa e a sua própria potência sexual.

"Sou um caboclo da roça.

Nascido dentro da mata

nunca calcei um sapato

nem botei uma gravata...

No dia que eu registrei

o meu menino mais novo,

o juiz estava nervoso

brigando no meio do povo.

Me chamou de maltrapilho sujo, plantador de milho,

disse mais uma piada

dessas que a boca não cabe:

"Matuto pobre só sabe

fazer menino e mais nada".

O juiz não tinha filho

que enfeitasse a sua vida.

Eu conheci a história,

fui direto na ferida:
"O senhor está zangado, tem dez anos de casado, A mulher não tem filho.. Minha família é grande dez filhos e a mulher.

A sua é muito pequena, mas é porque você quer! A sua mulher lhe embroma! Quase todo dia toma anticoncepcional, lhe vicia na novela, dorme tarde, faz tabela e lhe tira o principal! (...)

Escute aqui bacharel, conversa longa me atrasa! Quer ver a mulher ter filho? bote um plantador de milho para dormir na sua casa!"

Ressalte-se que o poema se refere ao que ainda hoje se observa: há mulheres com dificuldade em envolver o parceiro no processo, atribuindo este fato ao reflexo de outros tempos, em que vigor físico e potência sexual eram confundidos com capacidade reprodutiva, o que parece explicar porque os homens fogem do diagnóstico ameaçador reagindo com revolta diante da situação, que consideram inaceitável. Não é difícil que, na intimidade, alguns se tornem calados, nervosos e até agressivos.

Talvez seja por isto que, durante muito tempo, as clínicas de tratamento da infertilidade tenham sido vistas como um "clube do bolinha" às avessas sem a presença do homem, por ser mais conveniente centrar na mulher sempre a suspeita principal da infertilidade, pois, acima de tudo, pela própria resignação, estaria mais disposta a validar o tratamento. 
Outras pré-concepções povoam a cultura, quando o assunto é infertilidade, principalmente de um casal jovem. Raramente se pensa em ausência de coitos, porque parece pouco provável terem dificuldade em manter o ato sexual. No entanto, "[...] deixando de lado a dificuldade dos parceiros em consumar as relações sexuais, caso excepcional, existem raras indicações femininas e freqüentes indicações masculinas para se recorrer a inseminação artificial" (TESTART, 1998, p. 36).

Independente do cônjuge envolvido e das circunstâncias, a forma como o casal vai enfrentar a infertilidade é diversa. A tradição tem um peso determinante neste sentido, colocando a presença dos filhos quase como uma condição para a consolidação da família, o que os leva a uma montanha russa de sentimentos, comportamentos e sofrimentos.

\subsection{Montanha Russa}

Um número pequeno de casais enfrenta com naturalidade a infertilidade e a falta de filhos e constrói uma vida a dois de forma centrada e feliz. Uns encontram na adoção possibilidade eficiente de dar prosseguimento à vida. Outros se submetem à dificuldade de forma obsessiva, muitas vezes desgovernam suas vidas pessoais e a relação a dois. Colocam no projeto do "filho idealizado" todo sentido de suas vidas, frustrando-se mês a mês numa tentativa em vão de finalmente ter um filho em seus braços. O temor da possível infidelidade oriunda da incapacidade de gerar um filho surge.

A infertilidade não diferencia as classes sociais, mas assim o faz a solução desse problema. A classe economicamente mais favorecida tem maiores chances de adotar uma opção mais onerosa a mais eficiente, diferente de outros casais que precisam da ajuda financeira de amigos e família, ampliando, por isso, as expectativas, opiniōes e cobranças. Observar "seus caracteres em outra pessoa", éo motivo mais freqüente para que não apenas o casal, mais a "família" opte pela RA.

A RA não afeta apenas o financeiro. Há um desgaste orgânico, por conta de incontáveis injeções hormonais e seus inconvenientes "efeitos colaterais". Para alguns casais interfere na redistribuição de prioridades, de adiar a compra de um bem, ou as tão desejadas férias. Queixam-se de estarem com a vida "empacada" na medida em que outros projetos pessoais são adiados como o investimento num novo emprego, o simples ingresso numa academia de ginástica. Passam a apostar todas as fichas no processo. Há em seus lares um "quarto vazio". 
Em poucos dias, o resultado do exame irá modificar a vida do casal e algumas vezes de quem o rodeia. Um fracasso pode desfazer sonhos, abalar a estabilidade do par ou amadurecê-lo. Um resultado positivo pode devolver o sentido da vida e também a família extensa. Há ainda a possibilidade de se ter "emoção" redobrada diante da gravidez múltipla, o que nem sempre é visto com tranqüilidade, diante das implicaçôes financeiras e estruturais, além de significar risco para a gestante e os bebês.

Uma coisa é consenso: ninguém consegue entrar e sair de uma experiência em RA da mesma forma. Alegres ou frustrados, mais próximos ou mais distantes, confiantes ou desesperançados, normalmente o processo induz ao estresse do casal. Muitos inconvenientes podem ser superados posteriormente, mas o desgaste psicológico do par e ainda de cada um dos parceiros, que freqüentemente saem frustrados da experiência ao se defrontarem com seus ideais de perfeição humana atingidos, nem sempre serão vencidos.

A verdade é que, mesmo sendo um processo oneroso e incômodo, desgastante físico e psicologicamente, é crescente o número de casais que buscam a RA como forma de conseguir uma gravidez. Discussões à parte, a polêmica reflete a angústia do casal para não ser, "num pais onde se plantando tudo dă", infértil. "Uma árvore sem frutos", vivendo mês a mês as delícias diante da possibilidade de, quem sabe, engravidar e as dores na constatação do fracasso, uma animação suspensa (SCHAFFER, DIAMOND, 2002).

\section{Considerações finais}

Talvez a preocupação da equipe seja posicionar o casal de forma realista para lidar com as chances de fracasso, sabidamente maiores que as do sucesso. É preciso ter em mente que já tão "avaliado" e frustrado, o casal neste momento necessita de reforços positivos para se manter no "estado de animação suspensa". A fórmula de como manter um casal "motivado" para participar do processo e, ao mesmo tempo, preparado para lidar com um (muito) provável resultado negativo, parece ser o grande desafio para os técnicos que trabalham hoje com RA.

É importante ressaltar que, em toda a bibliografia consultada, nenhum autor dedica mais que algumas frases ao estado psicológico do casal, embora seja ponto comum considerar-se que o estado emocional do casal tem papel fundamental no processo e que o tratamento sobrecarrega o par. A necessidade sentida pelo casal em ser ouvido quanto aos seus receios, emoções e inseguranças, dificilmente cabem dentro da consulta médica. 
Empolgado com o amadurecimento do óvulo, muitas vezes o profissional sente dificuldade em entender que o "candidato a papai" teve dificuldades em cumprir o roteiro dos "coitos programados".

O sexo é uma expressão da vida. Tenso e ansioso, o casal, evidentemente modifica o jogo erótico-sexual. Privar o par da espontaneidade, talvez seja sua maior penalidade. Manter um coito preocupado com o dia do ciclo, esconder a mágoa de ontem e buscar um contato físico porque "hoje é o dia fértil”, a obrigação não apenas com a ereção, mas também em ejacular, são alguns dos fatores que precisam ser lembrados.

Enquanto os profissionais discutem, de um lado, como ampliar as chances de sucesso de um casal, melhorando técnicas e taxas, um segmento da sociedade mostra-se preocupado de forma cabível com a bioética que regulamenta também o trabalho em RA. Embora a ética e a bioética não tenham sido alvo de estudo do presente trabalho, seu trato é de suma importância. Infelizmente, em meio a tantos índices, exames, cifras, técnicas e opiniōes diversas, encontrase acuado o casal, necessitando urgente de um olhar sensível, mais humano e acolhedor.

\section{Referências bibliográficas}

BÍBLIA. Português. A Bíblia de Jerusalém. La Sainte Bible. São Paulo: Edições Paulinas, 1973.

BRASIL. Instituto Brasileiro de Geografia e Estatística. Dados populacionais. Disponível em: < www. ibge. gov. br >. Acesso em: 02/maio/2002.

CAVALCANTI, R.; CAVALCANTI, M. Tratamento clínico das inadequações sexuais. 2a ed. São Paulo: Roca, 1992.

GREGERSEN, E. Práticas sexuais: a História sexualidade humana. São Paulo: Rocca, 1983.

MALDONADO, M.T. P. Psicologia da gravidez. $10^{\mathrm{a}}$ ed. Petrópolis: Vozes, 1985.

MENEZES, R. O Planejamento familiar e a cultura popular. In MEDEIROS, A. O planejamento familiar e o Nordeste. Rio de Janeiro: Medsi, 1990, p 41-52.

OLIVEIRA, A. Eles sabem tudo. Será? Revista Veja. São Paulo, v. 38, p. 24-25, 2001.

RODRIGUES, O. Jr (org). Aprimorando a saúde sexual: Manual de Técnicas de Terapia Sexual. São Paulo: Summus, 2001. 
SCHAFFER, J. A,; DIAMOND, R. Infertilidade: dor pessoal e estigma secreto. In: IMBER-BLACK, E. (org.). Os segredos na família e na terapia familiar. Porto Alegre: Artes Médicas, 2002, p. 113-127.

SOUZA, A.M.N. A família e seu espaço: uma proposta de terapia familiar. $2^{\text {a }}$ ed. Rio de Janeiro: Agir, 1997.

TESTART, J. A fertilização artificial. São Paulo: Ática, 1998.

\section{Bibliografia Recomendada}

COSTA, J. F. Ordem médica e norma familiar. $4^{\mathrm{a}} \mathrm{ed}$. Rio de Janeiro:Graal, 1999.

FERNÁNDEZ, D.; URDAPILLETA, L. Aspectos psiconeuroendócrinos de la anovulación y de algunas alteraciones de la reproducción asociadas a condiciones psicológicas. Reproducción Humana, (Buenos Aires), v. 2, n. 2, p. 12-20, 2002.

FRIEDMAN, D. Uma mente própria: a história cultural do pênis. Rio de Janeiro: Objetiva, 2002.

GRAD, M. A. A princesa que acreditava em contos de fadas. Rio de Janeiro: Nova Era, 2001.

GRATCH, A. Se os homens falassem ... como compreender as atitudes masculinas. $2^{a}$ ed. Rio de Janeiro: Campus, 2001.

IMBER-BLACK, E. (Org). Os segredos na família e na terapia familiar. Porto Alegre: Artes Médicas, 2002, p. 113-127.

KAPLAN, H. A nova terapia do sexo. Rio de Janeiro: Nova Fronteira, 1977. LOPES, G.; GOODSON, L.; CAVALCANTI, S. (Org). Sexologia e ginecologia. Rio de Janeiro: Medsi, 1995.

MASTER, W.; JOHNSON, V. A incompetência sexual. 2 ed. Rio de Janeiro: Civilização Brasileira, 1970.

MEDEIROS, A.S. O Planejamento familiar e o Nordeste. Rio de Janeiro: Medsi, 1990.

MENEZES, V.; CARRION, C. Male sexual performance as seen by women. XIII World Congress of Sexology, Valencia: WAS, 1997 (no prelo).

MORRIS, D. O macaco nu. 12 ed. Rio de Janeiro: Record, 1993. SBRA (SOCIEDADE BRASILEIRA DE REPRODUÇÃO ASSISTIDA).

Disponível em: <www. sbra.com.br> Acesso em 24. 01. 04.

SERRANO, R.H. Terapia Sexual: Velhos e novos rumos. In: RODRIGUES JR., O. Aprimorando a saúde sexual: Manual de Técnicas de Terapia Sexual. São Paulo: Summus, 2001. p 9-11. 